\title{
ECONOMIC EFFICIENCY ANALYSIS OF DAIRY CATTLE FARMS IN BULGARIA
}

\author{
K. Stankov* \\ Department of Management, Economics Faculty, Trakia University, Stara Zagora, Bulgaria
}

\begin{abstract}
Dairy cattle production remains one of the traditionally most profitable sectors of agriculture and is at the same time among the most favored branches by farmers in Bulgaria. The aim of this article is to describe the present picture and provide analysis of its condition and economic efficiency, as well as to give recommendations for its improvement. The topic of dairy cattle and their products, especially milk, will always be an object of interest for agricultural economists. The relevance of the problem stems from the current unfavorable economic situation in Bulgaria, due to the global economic crisis and its impact on all segments of the production and consumption of dairy products. Some of the major results and conclusions made as a result of the study are that most of the of dairy cattle farms function on the edge of survival, which requires urgent rescue measures and subsequently, measures for their recovery. Appropriate recommendations are made at the end of the article to meet the objectives of the article.
\end{abstract}

Key words: dairy cattle, economic efficiency, economic crisis, rescue measures.

\section{INTRODUCTION}

Production efficiency has always occupied a central place in economic sciences, including agricultural economics. Therefore, as a category, it is at the basis of almost all economic indicators. It is the foundation on which $\mathbf{I}$. economic theory and practice are built. (1) This stems from the axis - and namely the primary contradiction in the economy - the contradiction between the needs and opportunities and the need for choice of alternatives. It is necessary to make a choice in the allocation and the usage of the resources, due to the fact that economic goods are scarce. Different ways of using the available resources can be presented as alternatives between which to make a choice. By selecting an alternative, higher economic efficiency can be provided in the economic system.

\footnotetext{
*Correspondence to: Konstantin Ivanov Stankov, Department of Management, Economics Faculty Trakia University, Stara Zagora, Bulgaria, Mailing address: Student Campus, 6000, Stara Zagora, Economics Faculty, Trakia University, Tel. (+359) 042699211 451, E-mail: kstankov@uni-sz.bg
}

The aim of the present article is to investigate the influence of the farm capacity on the economic efficiency level by different dairy cattle farms groups with different cow numbers in Bulgaria.

\section{CHARACTERISTISCS OF THE FARMS SURVEYED}

Dairy cattle breeding is the leading subsector, with the largest share in the gross domestic product in Bulgarian agriculture. It is prevalent in all regions, regardless of the geographical conditions of the country. Significant variety is seen in terms of capacity and farms, respectively in the number of cows per farm. In our study we covered part of the dairy cows grown in Central and South-Eastern Bulgaria in different size farms. Animals are predominantly Black and White breed and mostly Holstein-Friesian.

The data in Table 1 and Figure 1 and 2 show that the study covered 90 dairy farms with different capacities. The relative share of farms with 1 to 9 cows is the lowest $-8.9 \%$ of the farms and $0.44 \%$ of the cows. The reason for the low representation of small farms is the insufficient, sometimes complete lack of accountability in the farms. Farmers produce milk mainly for subsistence and a small portion remains available for processing. The 
farms are mostly of second category and with the lowest lactation milk yield. This information we accept as indicative, since most of the cows are representatives of small farms.

Table 1. Structure formed sample of farms with dairy cows.

\begin{tabular}{|l|l|l|l|l|l|}
\hline Indicators & $\begin{array}{l}\mathbf{1 - 9} \\
\text { small }\end{array}$ & $\begin{array}{l}\mathbf{1 0 - 4 9} \\
\text { middle }\end{array}$ & $\begin{array}{l}\mathbf{5 0 - 9 9} \\
\text { large }\end{array}$ & $\begin{array}{l}>\mathbf{1 0 0} \\
\text { very } \\
\text { large }\end{array}$ & $\begin{array}{l}\text { Total } \\
\text { average }\end{array}$ \\
\hline Number of the farms & 8 & 32 & 32 & 18 & 82 \\
\hline Total number of the cows & 29 & 732 & 2374 & 3336 & 6471 \\
\hline Average number of the cows & 3,6 & 22,9 & 74,2 & 185,3 & 71,9 \\
\hline $\begin{array}{l}\text { Average milk yield per } \\
\text { lactation }\end{array}$ & 3050 & 4489 & 5128 & 5872 & 5533 \\
\hline
\end{tabular}

In the group of medium-scale farms, representation is significantly better $-35.6 \%$ of the surveyed sector and $11.31 \%$ of the cows.
The average capacity is 22.9 cows. The milk yield is slightly above average for the country.

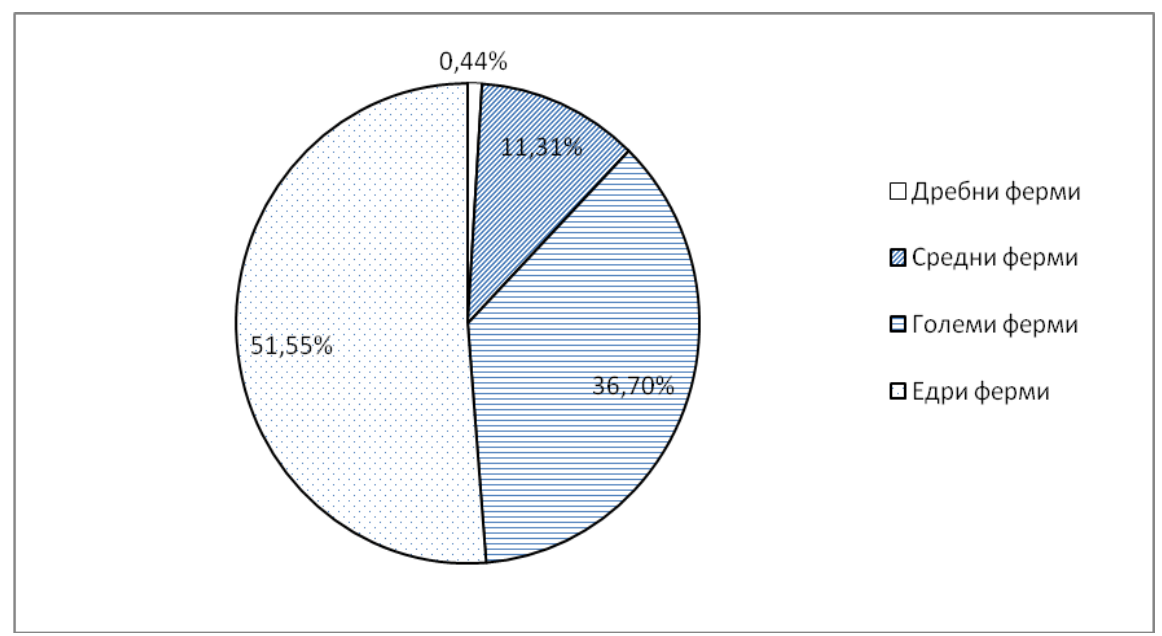

Figure. 1. Number of dairy cows involved in the study - in $\%$.

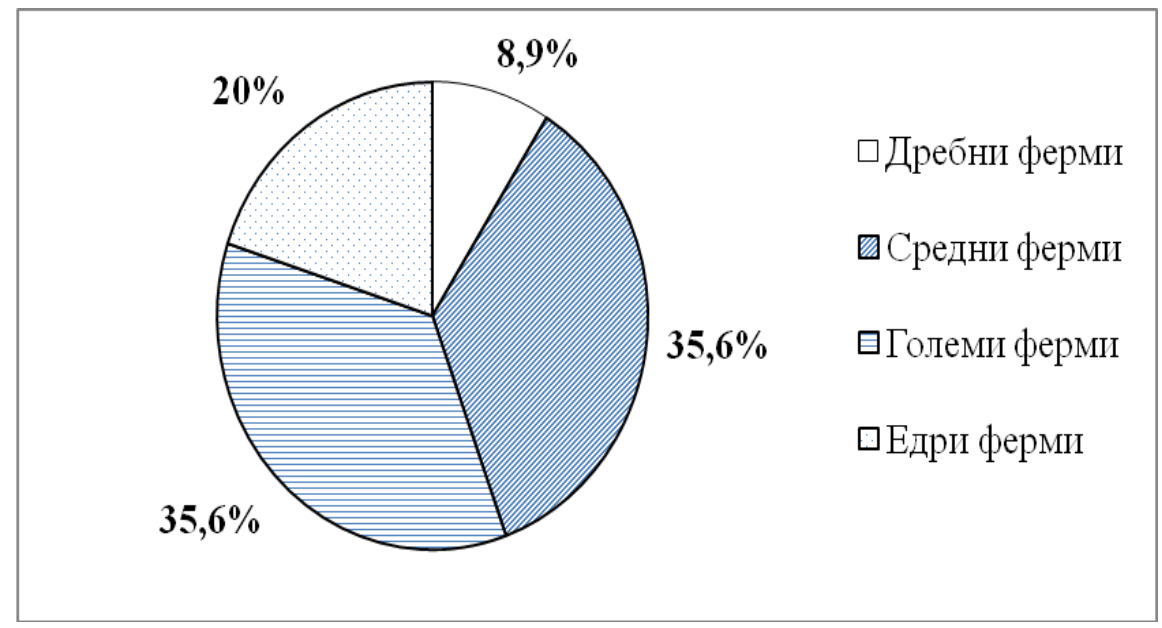

Figure. 2. Structure of dairy farms in Central and Southeastern Bulgaria surveyed in (\%).

The group of the large farms as it is defined and starting from the low average size of the country, the representation of farms is also $35.6 \%$ and of cows is respectively $36.70 \%$. The lactation milk yield is significantly higher than the national average. All farms in the groups of medium and large farms are in the first category and use the produced milk primarily for processing. 
Farms from the fourth group, with more than 100 cows, which have significantly greater capacity than the national average and the EU, have a share of $20 \%$, but the number of cows constitutes $51.55 \%$ of the total number of surveyed animals. The average milk yield of the group exceeds that of the country with about 39.3 percent. The number of cows in this group ranges from 104 to 895 .

The leading idea in our study was to cover and analyze the farms primarily in the first category, which largely provide milk for processing into dairies. The average for all animals included in the study of Central and Southeastern Bulgaria shows that the average farm breeds 71.9 dairy cows, which is above the average capacity for the country and for the European Union. The realized lactation milk yield of cows is above the national average, which shows that there is a gene pool in Bulgaria, necessary for the production of cow's milk.

The data obtained by us are close to those of the controlled Holstein population of cows, indicated by Dimitrov (2012) (2), although not all farms are in the group of selection herds.

Although small farms have little representation in the study and low milk production for lactation, they should be taken into consideration, because they provide half of the raw milk in the country. For this purpose, it is necessary, to contribute to their consolidation, through action by the MAF, the state and nongovernmental organizations, by increasing farm size and cooperation, bringing accounting and pedigree selection work and meeting the requirements for technological support.

In medium-scale farms, work must continue on genetic improvement and on increasing milk production for lactation by appropriate selection methods, as well as to work purposefully for the technological improvement of farms in order to fulfil certain EU requirements.

Large an very large-scale farms are promising for Bulgaria. The lactation milk yield achieved significantly exceeds the average milk yield for the country. They are at a good technological level, corresponding to the highest European criteria. They need to continue to work on increasing milk production and achieving the quantities of those in developed European countries and North America.

\section{LEVEL AND DYNAMICS OF ECONOMIC EFFICIENCY IN DAIRY FARMING}

In the transition from planned to a market economy, conditions for greater specializations of production in cattle breeding were created. Specialized dairy production has been given a priority, mainly involving animals of the motley black Holstein cattle population and especially those of the highest milk production breed in the world, the Holstein Friesian. As a result, significant changes occurred in the level of efficiency. Changes occurred not only in its most important components (manufacturing output and the cost of its production), but also in the relationships between the factors that have given rise to them. This requires the factors that determine the level of efficiency in dairy cattle breeding to be distributed, on the one hand by both qualitative and quantitative determination, and the other, in connection with their interdependence.

One of the main problems of this analysis is the difficulty in identifying the hidden factors that determine effectiveness. This is explained by the fact that it is difficult to ascertain the impact of the whole complex of factors only on the basis of the values of a selected synthetic indicator. In this sense, the proposed scheme of vertical decomposition of efficiency, which will serve as the structural basis of the forthcoming analysis, can largely give greater clarity in the raised above problem.

First, we analyze the income and expenditure in groups of farms per dairy cow, and respectively, their profitability as a leading indicator determining the effectiveness.

The data shown in Table 2 reflect the impact of farm size on the economic fundamentals determining the economic viability of the farm. With the increase in the capacity of the farm also increases the amount of revenue. This is due to better opportunities for technological improvement of feeding and rearing - better organization of production, and those for a more - successful and purposeful selection of the merged farms. All this helps to achieve higher milk yield and better quality milk, and hence getting more revenue.

In terms of costs, we can observe the same trend, where the least cost is reported in small farms, and the highest, in large ones. In the former case, this is explained by the failure to take account of labor input and maximum use of grazing, as a major source of livestock feed. In merged farms, the cost of more rational nutrition is higher, with a view to the higher productivity of cows, as well as the need of greater investments of more fixed and variable costs. Logically, from the received revenues 
and incurred costs, profits and the profitability of revenue and expenditure are greater. This can be seen more clearly from Figures 3 and 4.

On the first level, the indicator costeffectiveness has determining influence in the analysis of the results. In a continuing situation of limited material and labor resources in dairy farming, profitability is highly dependent on their effective use in production.

Table 2. Revenues, expenses and profitability of production in dairy farming for 2010-2012

\begin{tabular}{|c|c|c|c|c|c|c|c|}
\hline 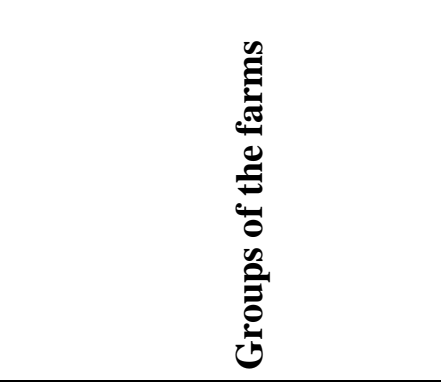 & 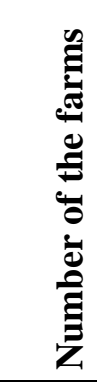 & 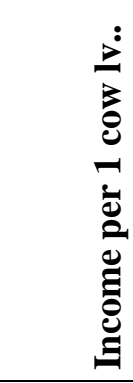 & 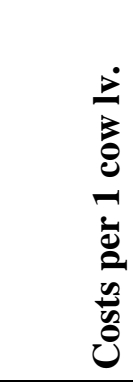 & 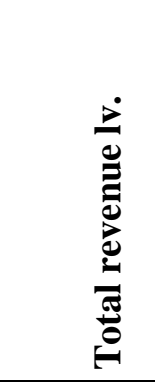 & 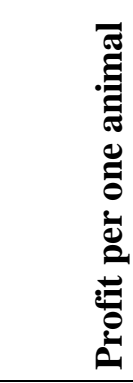 & 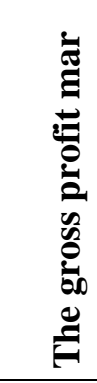 & 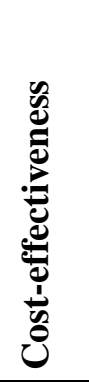 \\
\hline Small from 1-9 cows & 8 & 2134,3 & 1563,0 & 2776,7 & 571,3 & 26,8 & 36,6 \\
\hline Middle from 10-49 cows & 32 & 3142,0 & 1953,2 & 27223,5 & 1188,8 & 37,8 & 60,9 \\
\hline Large from 50-99 cows & 32 & 3590,0 & 2123,6 & 108806,9 & 1466,4 & 40,8 & 69,1 \\
\hline Very large from 100 cows & 18 & 4110,3 & 2362,4 & 323885,9 & 1747,9 & 42,5 & 74,0 \\
\hline Average for the farms & 90 & 3872,9 & 2257,6 & 461973,0 & 1615,3 & 41,7 & 71,5 \\
\hline
\end{tabular}

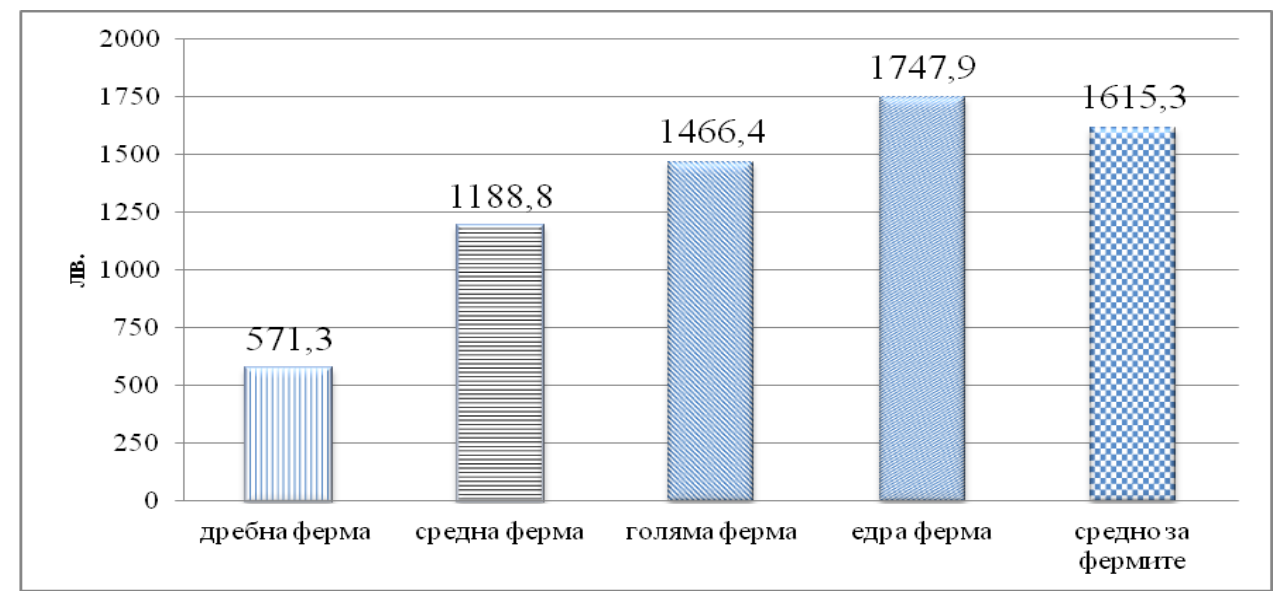

Figure 3. Profit per animal groups farms.

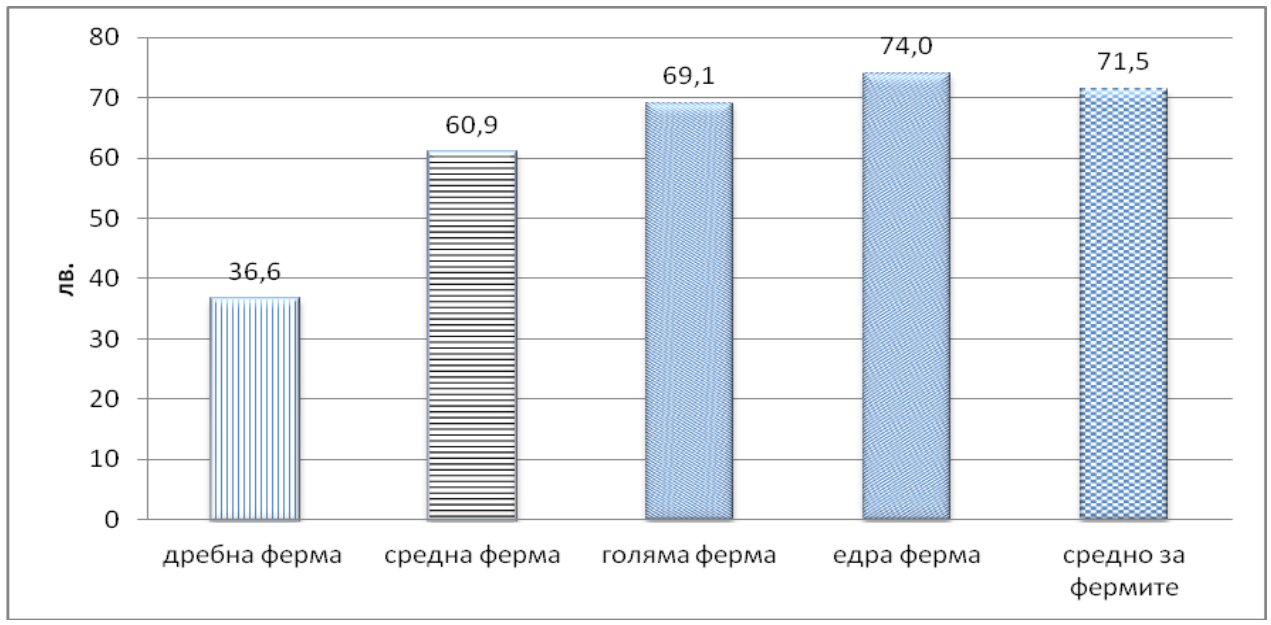

Figure. 4. Cost-effectiveness in groups farms

Trakia Journal of Sciences, Vol. 13, Suppl. 1, 2015 
The coefficient of efficiency gives the most accurate information about the results of complex utilization of the factors of production in dairy cattle breeding. It greatly contributes in the process of determining of the possible reimbursement of the production costs incurred.

The data listed in Table 3 show that the highest cost returns have large and very large- scale farms, without taking into account the amount of subsidies. Since the relative share of these two groups of farms included in the survey is the largest ( $88.2 \%$ of the cows), the general average of the efficiency ratio of all farms is high - 1.71. This is a prerequisite for the greater cost return in the merged farms included in the study.

Table 3. Efficiency (economic) of the dairy cattle in Bulgaria.

\begin{tabular}{|l|l|l|l|l|l|}
\hline Indicators & $\begin{array}{l}1-9 \\
\text { small }\end{array}$ & $\begin{array}{l}10-49 \\
\text { middle }\end{array}$ & $\begin{array}{l}\mathbf{5 0 - 9 9} \\
\text { large }\end{array}$ & $\begin{array}{l}>100 \\
\text { very large }\end{array}$ & $\begin{array}{l}\text { Total } \\
\text { average }\end{array}$ \\
\hline Coefficient of efficiency & 1,36 & 1,71 & 1,78 & 1,82 & 1,80 \\
\hline Coefficient of income rate & 1,5 & 1,68 & 1,80 & 1,83 & 1,75 \\
\hline $\begin{array}{l}\text { Profitability rates } \\
\text { (in\%) }\end{array}$ & $\mathbf{3 6 , 0}$ & 71,0 & 78,0 & 82,0 & 80,0 \\
\hline
\end{tabular}

Source: Calculated on the basis of its own information

In terms of the profitability ratio of retail production, small farms remain relatively well. This can be explained largely by family involvement and maximum utilization of natural resources. However, these farms have the lowest rate of return - 36\%, which again shows that due to the low productivity of the animals and low production realization, economic efficiency is unsatisfactory.

Medium-scale farms have comparatively lower rates of these indicators but still they are closer to those of large an very large-scale.

Large an very large-scale outperform the other two groups in terms of rates of profitability and cost-effectivenss. It is very significant that the dairy cows of the cultured highly productive breeds successfully realize their biological potential and achieve relatively good economic performance, when backed by technology.

The economic efficiency of dairy farming is changing in a positive direction, taking into account the impact of public support. The incurred production costs can largely be offset through various forms of subsidies.

The results of the analysis of public support are presented on the Table 4.

Table 4. Efficiency of dairy farming subsidies based on income profitability.

\begin{tabular}{|l|l|l|l|l|l|}
\hline Indicators & $\begin{array}{l}1-9 \\
\text { small }\end{array}$ & $\begin{array}{l}\mathbf{1 0 - 4 9} \\
\text { middle }\end{array}$ & $\begin{array}{l}\mathbf{5 0 - 9 9} \\
\text { large }\end{array}$ & $\begin{array}{l}\text { > 100 } \\
\text { very large }\end{array}$ & $\begin{array}{l}\text { Total } \\
\text { average }\end{array}$ \\
\hline $\begin{array}{l}\text { Coefficient of } \\
\text { efficiency }\end{array}$ & 1,36 & 1,71 & 1,78 & 1,82 & 1,80 \\
\hline $\begin{array}{l}\text { Coefficient of } \\
\text { income rate }\end{array}$ & 1,5 & 1,68 & 1,80 & 1,83 & 1,75 \\
\hline $\begin{array}{l}\text { Profitability } \\
\text { rates } \\
\text { (in\%) }\end{array}$ & $\mathbf{3 6 , 0}$ & 71,0 & 78,0 & 82,0 & 80,0 \\
\hline
\end{tabular}

Source: Calculated on the basis of its own information

Production efficiency is highest (1.78 and 1.82) again in the group of the large an very large-scale with more than 50 dairy cows, but the increase is not significant, with about $5.2 \%$. More significant increase was observed in the same group in terms of the profitability coefficient with $15.4 \%$ in big and $13.7 \%$ in large-scale farms, and a rate of return of about $13.0 \%$ in big and $12.3 \%$ in large-scale farms. Data show that the subsidy has certain positive impact on economic efficiency in the merged farms.
In medium-scale farms, the efficiency ratio increased by $6.9 \%$, the yield by $17.5 \%$, and profitability, by $18.3 \%$. Therefore, the effectiveness of subsidies in the medium-scale farms is influenced to a greater extent in a positive direction. This helps to release certain percentage of funds for the modernization of milk production and income support for farmers.

In the group of small farms, no changes have been observed, as most farms do not receive subsidies for most of the measures. Given the 
shortage of raw milk and the large imports of dairy products from outside, is necessary for small farms to modernize.

According to Dardzhonov (3) (2012) in Poland, Slovenia and Austria, the size of farms is almost as much as in Bulgaria and the majority of them are small. However, all animals are subsidized and traditionally small farms produce cow's milk in these countries.

In order to increase the efficiency of Bulgarian dairy cattle in the new programming period, following Programme 2020, the subsidy should be increased and Bulgarian milk producers must catch up with older EU member states in terms of subsidizing.

Further consideration of profitability requires tracing it throughout the study period, which lasted 3 years. Figure 5 shows that the profitability of cost increased every year and in 2012 it was higher by $20.5 \%$ compared to 2010.

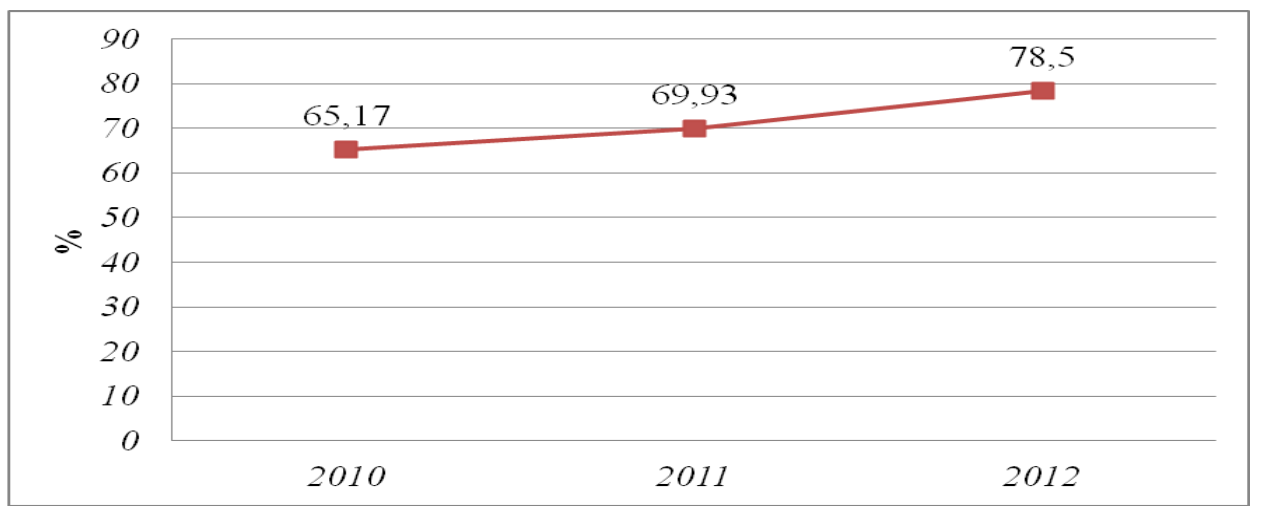

Figure 5. Profitability of expenditure for the period 2010-2012 for dairy farming in Central and Southeastern Bulgaria.

The greater cost-effectiveness is due to the more efficient use of the means of production and especially of the biological fixed assets, which annually improve in the surveyed farms in Central and Southeastern Bulgaria. As most favorable in terms of profitability of total expenditure manifests the year 2012, when 100 lev total cost wore 78.5 lev profit.

An important part of the study of profitability is also establishing the return on dairy cow, which will complete the picture of the economic status of dairy farming in Central and Southeastern Bulgaria (Figure 6).

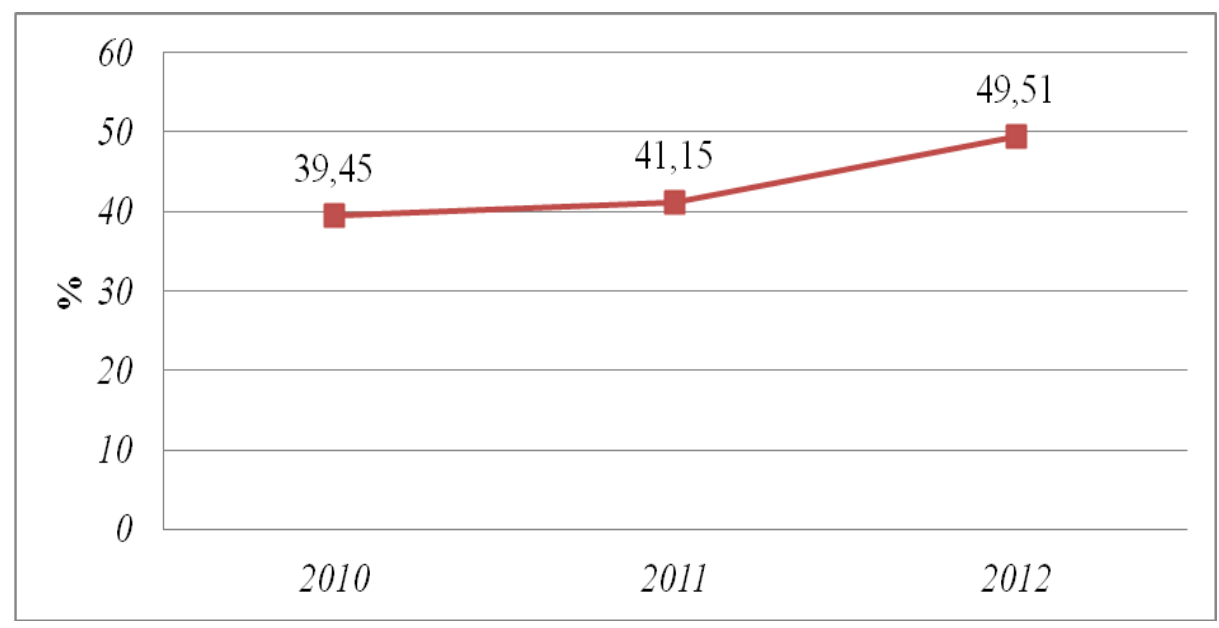

Figure 6. Gross profit margin of dairy cow for the period 2010-2012 for dairy farming in Central and Southeastern Bulgaria.

The data for the values of this index confirm the conclusion that was made for the indicator cost-effectiveness. There are satisfactory levels of profitability and revenue for the three years under consideration. Again the highest value is in 2012, which gives reason to believe that it is the most successful year in dairy farming for the observed period. 


\section{CONCLUSION}

The data on the impact of farm size on the economic fundamentals, especially on profits and the profitability of revenues and expenditures show that big and especially large-scale farms significantly outperform small and medium ones. For the former, costeffectiveness is respectively $69.1 \%$ and $74 \%$, which excel significantly that of small-scale farms.

The survey results also show that public support increases the rate of return of all farms, while this is more significantly expressed in medium-scale farms.

Our recommendation is to increase the amount of the subsidy, which should be aligned with that of the old Member States of the European Union.

\section{REFERENCES}

1. Kovachev, Economic Theory Part I. Microeconomics. University Press University, Varna, p. 9-20, 78-80.

2. Kovachev, H. 1996. General Economic Theory Part II. Macroeconomics. University Press University, Varna.

3. Dardzhonov, Tr. 2012. Creating and maintaining a milk dairy farm. EASRAB site.
4. Dardzhonov, Tr. 2012. Where is the exit for the production of quality milk. EASRAB site.

5. Dimitrov, F., M. Koleva, N. Vassilev, P. Petkov, M. Dimitrov. 2005. Relationship between number of somatic cells and bacterial finding in mlya $\neg$ koto of cows early motitoring health of the breast. Trskia Journal of Science, 3, suppl.2: 42-45.

6. Stankov, Vl. 1978. Methodological problems of economic analysis of efficiency in livestock. Economic Thought, p. 24-33.

7. Stankov, V1. 1985. Economics and Organization of livestock Zemizdat Sofia.

8. Stankov, I. et al. 2009. National program for development of dairy farming in Bulgaria, 2009-2013.

9. Stankov, I. et al. 2013. National Strategy for sustainable development of Bulgarian agriculture 2014-2020.

10. Stankov, I. et al. 2002. Problems of livestock production in Bulgaria. Scientific-practical conference, St. Zagora 22-23 May with. 16-17. 